\title{
A SIMPLE METHOD OF BRAIN DISSECTION
}

\author{
PAUI, E. LINEBACK \\ Harcard Medical School \\ FIVE FIGURES
}

Every instructor realizes how hard it is to make clear to students the deep or inner structures of the brain. It is difficult to give them a lucid description of even the simpler and more superficial parts, but when it comes to explaining the intricate mechanism, it is an almost hopeless task.

Efforts have been made to disclose the regions, parts, tracts, and nuclear masses by means of a series of cross sections or fiber tract dissections. To all but those well trained in technique and familiar with the general make-up of the brain, these methods are confusing and difficult. Tract dissection necessitates a general understanding of how and where a tract runs, and a series of cross sections presents to a student a mass of labyrinthian vagaries. Most students remember an important structure in a cross section series as it appears in a few well-defined segments, but do not have a clear mental picture or distinct understanding of its extent and relationship. With the following method a student, being guided by a few easily located landmarks, can get the greatest degree of clearness and satisfaction from his work, and have the least amount of cutting and mutilating of tissue.

The procedure is as follows: Using one-half of the brain, clear away all pia mater from the regions to be cut; sylvian fissure, central fissure (Rolandi), post central fissure, superior frontal sulcus, and about the uncus and temporal pole. This is important to make the field of operation perfectly clear and prevent blocking the knife. It is also important to use a long scalpel, the blade of which should be about 7 or $8 \mathrm{~cm}$. long and not more than $1 \mathrm{~cm}$. in width; $0.5 \mathrm{~cm}$. is still better. Place the hemisphere with frontal region upward or toward the student and depress the temporal pole sufficiently clearly to expose the uncus. Now cut across the upper part of this convolution, going from within outward and slightly downward, extending the cut about $2 \mathrm{~cm}$. lateralward and the same backward (fig. 1). Make further depression of the temporal lobe there by widening the sylvian fissure, and cut at nearly right angle to the first incision along the lower border of the island (fig. 1). When this cut is extended 2 or $3 \mathrm{~cm}$. directly backward, the tip of a cavity can be exposed, the anterior extremity of the inferior horn of the lateral ventricle. 

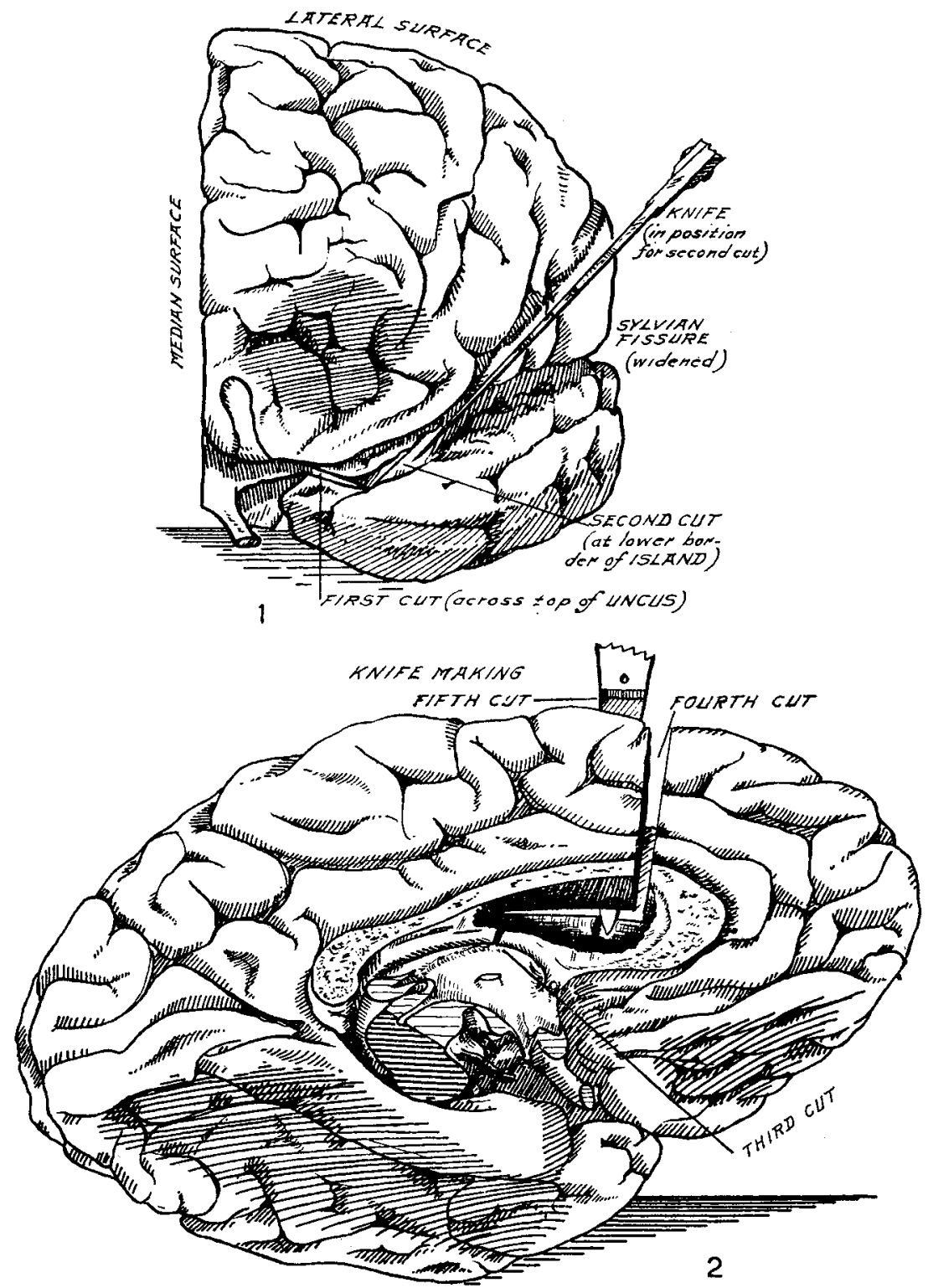

Fig. 1 Showing hemisphere in position, frontal pole forward and temporal pole depressed to make first and second cuts.

Fig. 2 Showing median surface with third and fourth cuts made and knife in position making fifth cut. 

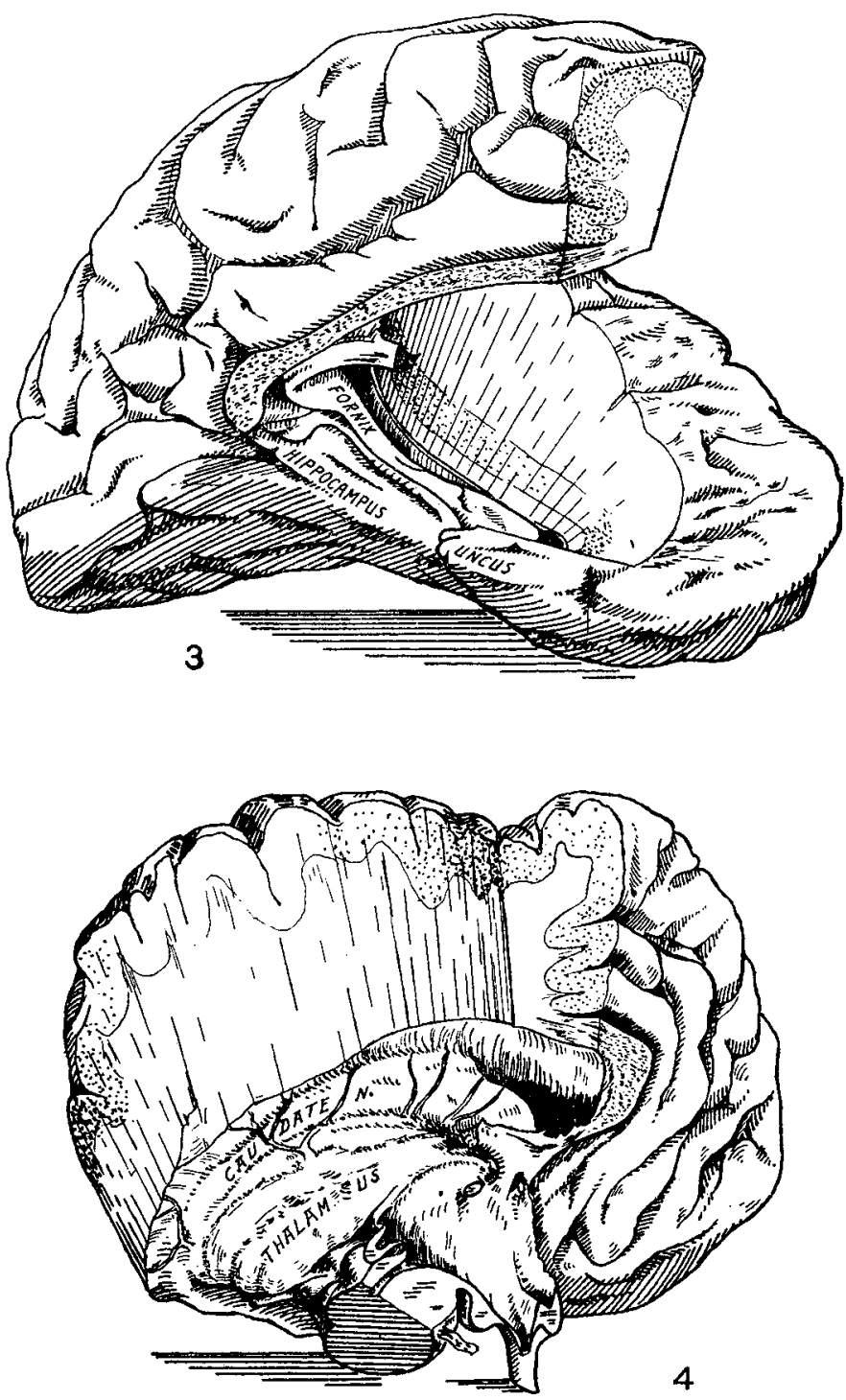

Fig. 3 Showing 'removable' portion, with hippocampus, fornix, and inferior horn of lateral ventricle.

Fig. 4 Showing 'basal' portion with lateral ventricle and its floor and lateral boundary structure in clear view. 
Going now to the median surface of the hemisphere, cut the fornix just back of the foramen of Monroe (fig. 2). Make another cut into the surface of the hemisphere, beginning the incision at a point on the under surface of the corpus callosum just back of where it makes its turn downward, and terminating it on the superior median border a little anterior to the beginning point or directly above the tip of the corpus callosum (genu), thus making an oblique cut. The depth of the incision should extend as far as the superior frontal sulcus on the lateral surface or about $2 \mathrm{~cm}$. from the superior median border, and to the lateral-most extent of the lateral ventricle or just above the caudate nucleus (figs. 2, 5). Now turn the knife at right angles to this plane

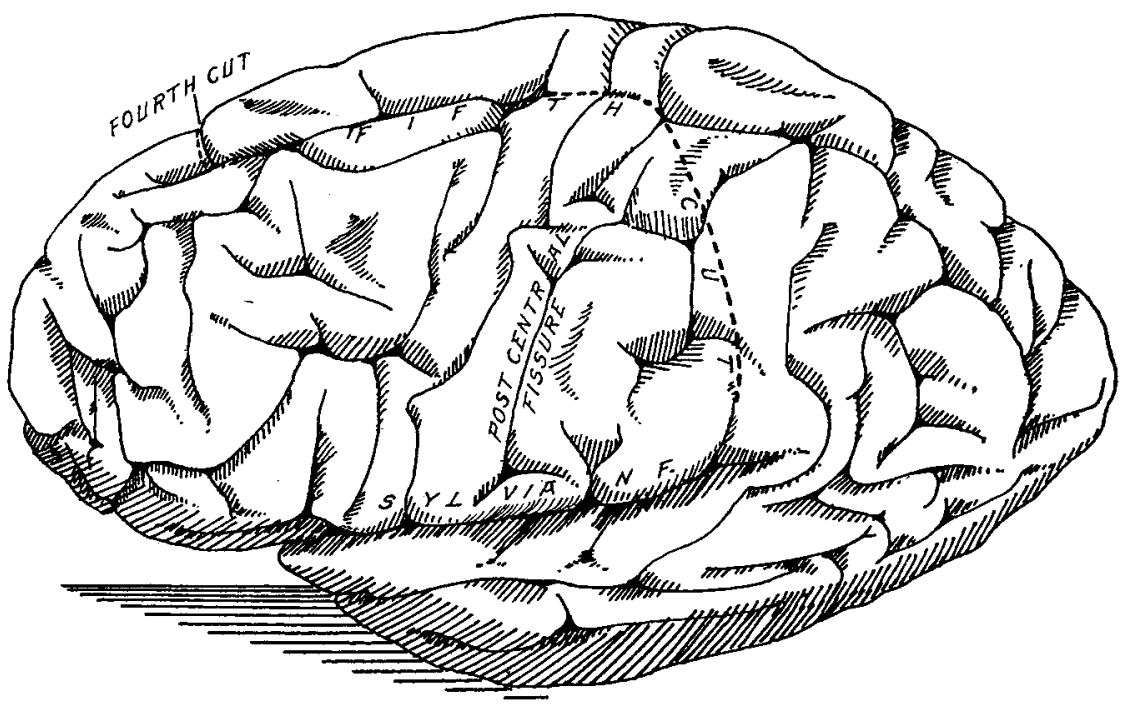

Fig. 5 Showing lateral surface and dotted line marking, on the surface, the course of the shoulder of the knife in making the fifth cut.

and make the following incision with the shoulder of the knife following the superior frontal sulcus or an arbitrary line at about this position, and the point following the lateral-most boundary of the ventricle, cut slowly and gradually backward, all the while elevating the excised portion to give clear view of the field (f.gs. 2,5 ). When the knife comes to the post central fissure, let it swing in a sharp curve downward and backward to the posterior end of the sylvian fissure, reaching this point by following the upper terminal arm of the fissure (fig. 5). While making this curve, the knife should be held with the handle tilted backward so that the point will be a little anterior to the shoulder. This will insure the point cutting through the ventricle at its lateral-most boundary where that cavity turns downward. When 
the shoulder comes to the sylvian fissure, lift the handle to about $60^{\circ}$ with the horizontal plane, thus forcing the point downward, at the same time turning the sharp edge forward.

Now make a little more bold depression of the temporal lobe through the sylvian fissure, and continue the incision forward along the lower border of the island to meet the original cut at the uncus, all the while holding the knife at about $60^{\circ}$ with the horizontal plane.

The incisions have now been completed. With the median surface facing upward, grasp the frontal lobe in the right hand and the occipital lobe in the left hand (this is for the left hemisphere; if the right hemisphere is used, the hands will be reversed), and carefully separate the two portions to about $3 \mathrm{~cm}$. This will stretch out the choroid membrane which can be casily followed almost throughout its entire extent of attachment. When this is carefully studied, the removablo portion containing the hippocampal lobe with its fornix can be entirely withdrawn, and a clear view of the lateral ventricle will be had (fig. 3 ). The complete separation of the two parts will rupture the choroid membrane, but the ragged edges will still give a clear view of the line of its attachment. On the basal portion, in plain view, will be the structures forming the floor and lateral boundary of the lateral vent ricle, caudate nucleus, tacnia semicircularis, thalamus, etc. The optic tract, geniculate bodies, quadrigeminal bodies, and pes redunculus can also be casily seen (fig. 4). The two segments can be easily, quickly, and repeatedly separated with no harm whatever to continuity of tissue. When the sections are in place, the cuts are scarcely perceptible; when removed, there is the greatest amount of exposure of hidden structures. A special advantage in this method is that specimens too soft for fiber tract dissection or cross sectioning, or hardened after boing mashed or pressed out of shape, can still be used with a good degree of satisfaction when eut as outlined above. There is to be offered this last and most important point, that the removable segment comes off from the basal portion in approximately the same course the hemisphere pursued in its early stages of development. Following this course of development as displayed by such a mothod of removing part of the hemisphere, it is much easier for the student to see how the velum interpositum was at one time a part of the wall, the roof portion of the forebrain, of the neurat tube, and its presence in the fully developed specimen, attached to the sharp odge of the fornix on the one side and the taenia semicircularis and thalamus on the other, makes a closed cavity of the lateral ventricle and its horn.

This method is not to be used for complete work; the nuclear masses and fiber tracts demand deeper dissection. But using the method on one hemisphere and cross section on the other. the student will have far greater and more gratifying results, and will have good material, easily kept, for future reference.

Finally, I wish to express my appreciation to Dr. IBremer and Mr. Miller for their kindness in reviewing this paper and making valuable suggestions. 